\title{
THE DAMAGES OF KSIAZ CASTLE ARCHITECTURE IN RELATION TO ROUTES OF RECOGNIZED TECTONIC FAULTS AND INDICATIONS OF RECENT TECTONIC ACTIVITY OF SWIEBODZICE DEPRESSION OROGEN - CENTRAL SUDETES, SW POLAND
}

\author{
Damian KASZA $^{1) *}$, Marek KACZOROWSKI ${ }^{2)}$, Ryszard ZDUNEK ${ }^{2)}$ and Roman WRONOWSKI ${ }^{2)}$ \\ 1) Wrocław University of Technology, Institute of Mining Engineering, $15 \mathrm{Na}$ Grobli St., \\ 50-421 Wroctaw, Poland \\ 2) Space Research Centre, Polish Academy of Sciences, 18 A Bartycka St., \\ 00-716 Warsaw, Poland \\ *Corresponding author's e-mail: damian.kasza@pwr.edu.pl
}

\begin{tabular}{l} 
ARTICLE INFO \\
\hline Article history: \\
Received 27 January 2014 \\
Accepted 17 June 2014 \\
Available online 1 July 2014 \\
\hline
\end{tabular}

Keywords:

Water-tube tiltmeters

Non-tidal signals

Tiltings of foundation

Recent tectonic effects

Faults

Tectonic impact on architecture

Ksiaz

Swiebodzice Depression

\section{ABSTRACT}

Recent tectonic activity in the area of Swiebodzice Depression is recorded by the instruments of underground Geodynamic Laboratory (GL) of Space Reseach Centre, Polish Academy of Sciences (SRC PAS). Irregular in time tectonic events lasting dozen or so hours or several days have been watched by pendulums tiltmeters since 1974. Indications of tectonic activity such as tiltings of foundation and vertical motions are repeatedly observed by water-tube tiltmeters (WT). The effects of tectonic activity in the region of Ksiaz are visible in the geological structure of the orogen as well as deformations of Pelcznica Valley meander.

Zones of discontinuity in the environment of undeground laboratory as well as objects of the castle were determined by geodetic measurements at established geodetic horizontal network and precise geological and structural identification. Geodetic horizontal network in underground corridors of GL was established in the first phases of the work. Construction of the network gives opportunity to designate the locations of faults and their projection onto the terrain map. The faults were measured by geodetic methods to determine their routes and dips.

Simultaneously, works on identifying damages of Ksiaz Castle architectural objects were conducted, the appearance of which suggested connection with the activity of tectonic faults. Some worrisome cracks in the castle architectural objects can be seen in the structure of wall of St. George Tower, in the wall of Chestnut Terrace as well as in the western wall of terraces (fragments repeatedly repaired). It has been found that the zones of above-mentioned damages are approximately linear and in the azimuth close to the faults route directions.

The tasks presented in publication represent initial part of the work, which is necessary for further progress of tectonic activity investigation in the Ksiaz area. In following research works focused on evaluation of the influence of tectonic activity on the castle architectural objects the two sources of information will be used, i.e. local information based on time series from GL and information from field measurements using geodetic research network.

\section{INTRODUCTION}

The presented study is a part of research program conducted at the Geodynamic Laboratory of Space Research Centre (GL) in Ksiaz in Lower Silesia, Poland. In the early 70 s of the last century prof. Roman Teisseyre founded in underground tunnels beneath the Ksiaz Castle a Geophysical Observatory belonging to the Institute of Geophysics of Polish Academy of Sciences. Initial work included seismic research, which since the mid-70s was extended to the tidal study conducted by prof. Tadeusz Chojnicki using horizontal quartz pendulums. In the early years of the XXI century in Ksiaz was founded GL. In the underground appeared new measuring instruments: water-tube tiltmeters, relative and absolute gravimeters and interference extensometer. The research program has been enriched with a wide range of nontidal phenomena research including recent tectonic activity of the Sudetes.
The presence of strong non-tidal signals in the form of tiltings of foundation as well as vertical motions have been observed in the GL for many years. Since the 70 s of the 20th century, i.e. from the beginning of activation of quartz horizontal pendulums, irregular instability of their equilibrium which indicate effects of tiltings of foundation were registered. In few days pendulums rapidly changed their azimuths of measuring positions (Chojnicki and Blum, 1996). Installation of long water-tube tiltmeters (WT) in 2002 (Kaczorowski, 2006) confirmed existence of this phenomenon. WT repeatedly recorded events of strong effects of variations in water level, which were equivalent to the non-tidal effects of the range 100 m.a.s. since the moment of their installation (Kaczorowski, 2008, 2009b).

Observations of phenomena obtained using different types of instruments in the form of irregular events lasting from a few to several dozen days (with 


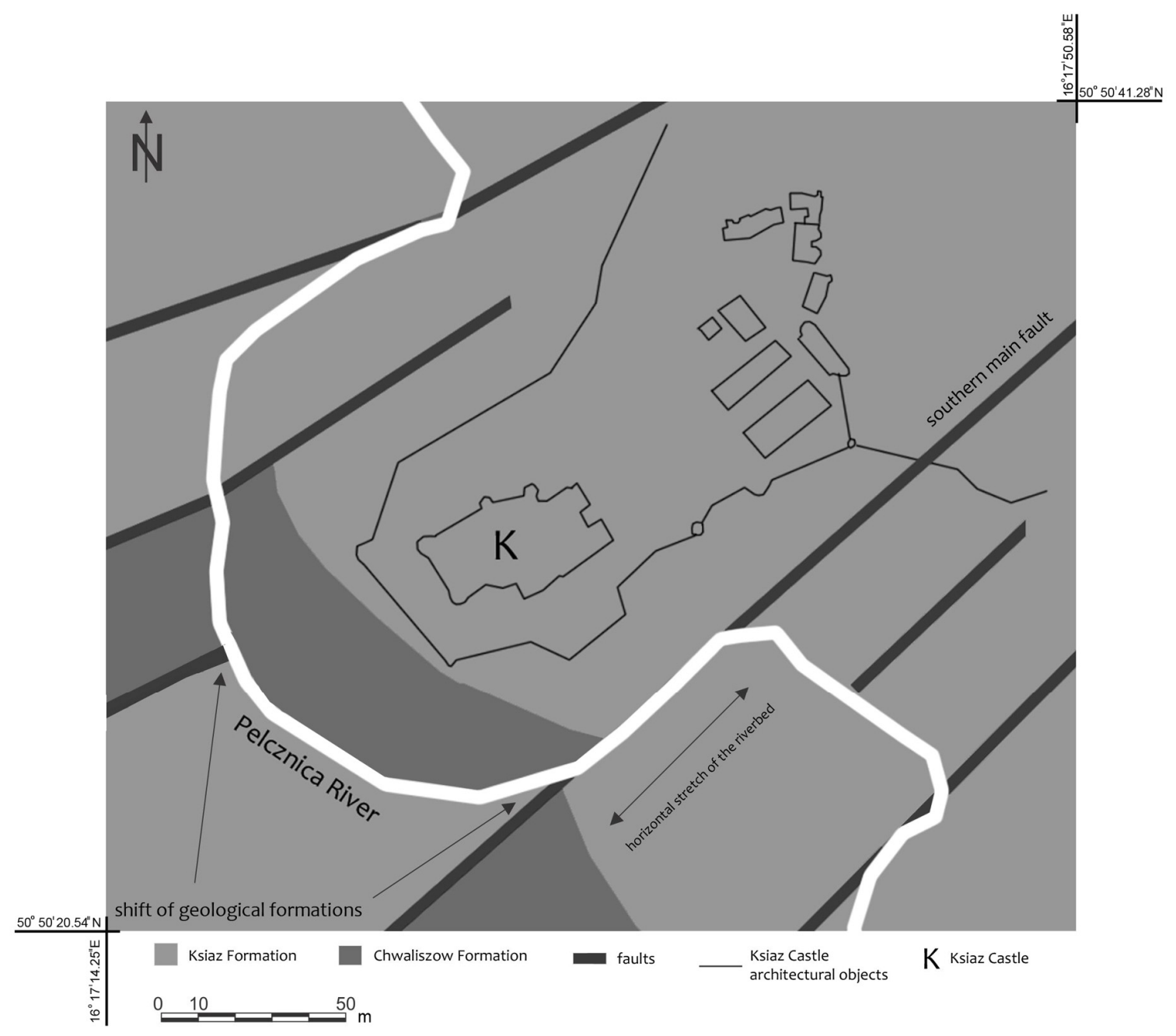

Fig. 1 Geological map of Ksiaz Castle area (Kaczorowski and Wojewoda, 2011, modified).

similar waveforms) confirm geodynamical (not instrumental) genesis of the received signals (Kaczorowski 2009a, 2009b; Kaczorowski and Wojewoda, 2011). The repeatability of the phenomenon, firmness of bedrock (very hard, nonabsorbent gneiss conglomerates) and overlap between distribution of castle damages and known fault lines exclude the effect of gravity causing that the rock mass splits. However, the morphology of the area indicates that the small part of the signal with the systematic nature can be caused by gravitational splitting of the rock mass.

The vertical movements and the slope of the ground observed by tiltmeters are a secondary effect of tectonic deformation resulting from the transformation of primary horizontal movements on inclined dislocation surfaces. For this reason, we expect that the size of the displacement caused by horizontal movements is at least an order of magnitude greater than those vertical displacements. Therefore, the impact of horizontal displacements on the architectural elements of the castle should be greater than of the vertical displacements.
The results of the impact of recent tectonic activity can be seen both in geological structure of the rock mass in the area of research (distinct dislocation lines) as well as in deformations of the Pełcznica River meander valley (Teisseyre and Sawicki, 1955; Teisseyre, 1969; Walczak-Augustyniak, 1988; Kaczorowski and Wojewoda, 2011) (Fig. 1).

\section{GEOLOGICAL AND TECTONIC STRUCTURE OF THE RESEARCH AREA}

The Ksiaz Castle is located in the central part of the Sudetes in the Walbrzych Foothills area (SW Poland). From the geological viewpoint the Ksiaz orogen is located almost in the central part of the geological structural unit of Swiebodzice Depression (Grocholski, 1969). The Depression is a mountain sedimentary basin of variscan age with the NW-SE direction (Oberc, 1978; Nemec et al., 1980; Ziegler, 1990; Żelaźniewicz and Aleksandrowski, 2008). Sediments within the Swiebodzice Depression are of the Upper Devonian and Lower Carboniferous age (Oberc, 1972). Highlighted are: Ksiaz Formation, Chwaliszow Formation, Pelcznica Formation, 
Pogorzala Formation as well as volcanic and metamorphic rocks of Kaczawa Complex.

Research area (surroundings of the Ksiaz Castle) is a border area between Kulm Chwaliszow Formation and Kulm Ksiaz Formation. In this area we deal only with characteristic petrographic varieties of these two formations: conglomerates, sandstones, gneiss boulders, migmatites and light gray granites (Teisseyre, 1951; Teisseyre and Gawroński, 1965; Porębski, 1981; Marcinowski et al., 2004).

In terms of tectonic conditions the structure of Ksiaz area as well as the whole Swiebodzice Depression is much more complicated. The unit is cut by numerous zones of dislocations (Teisseyre and Sawicki, 1955; Haydukiewicz et al., 1962; Teisseyre and Gawroński, 1965; Teisseyre, 1969; WalczakAugustyniak, 1988; Stepancikova et al., 2010). Some of them are located within the measure basis of the GL instruments which allows for the registration of the effects of recent tectonic movements in the form of tiltings of foundation and vertical motions.

The effect of modern deformation of the Pełcznica River meander valley (surroundings of the Ksiaz Castle) along active faults is visible in the form of shifted geological formations (Fig. 1). The regular river meander has been partially stretched in the SW$\mathrm{NE}$ direction which is consistent with routes of documented faults (Teisseyre and Sawicki, 1955; Teisseyre and Gawroński, 1965; Teisseyre, 1969; Walczak-Augustyniak, 1988; Kaczorowski and Wojewoda, 2011).

\section{ENVIRONMENT OF GEODYNAMIC LABORATORY}

The system of underground tunnels used by GL is located at a depth of 50 meters directly under the courtyard of the Ksiaz Castle. They are the residue of the Nazi military facility built in the last years of World War II (Dudziak, 1996; Aniszewski and Zagórski, 2006). Mine workings are in approximate outline of regular grid with tunnels of total length of about 950 meters. A significant number of corridors are unprotected (without roof support systems), which allows watching the course of geological structures faults - in the area of laboratory (Fig. 2). The galleries used by the laboratory are horizontal. Their temperature and humidity conditions are stable and facilitating operation of instruments used in the study of tectonic phenomena, i.e. two water-tube tiltmeters (Kaczorowski, 2006), two pairs of horizontal quartz pendulums and vacuum interference extensometer (made by M. Kaczorowski).

\section{DETERMINATION OF FAULTS PARAMETERS IN GL CORRIDORS}

The location of Geodynamic Laboratory in underground tunnels provides unique opportunity to observe and study the orogen from the inside. Locations and routes of tectonic faults on the surface of Earth in surroundings of castle buildings are

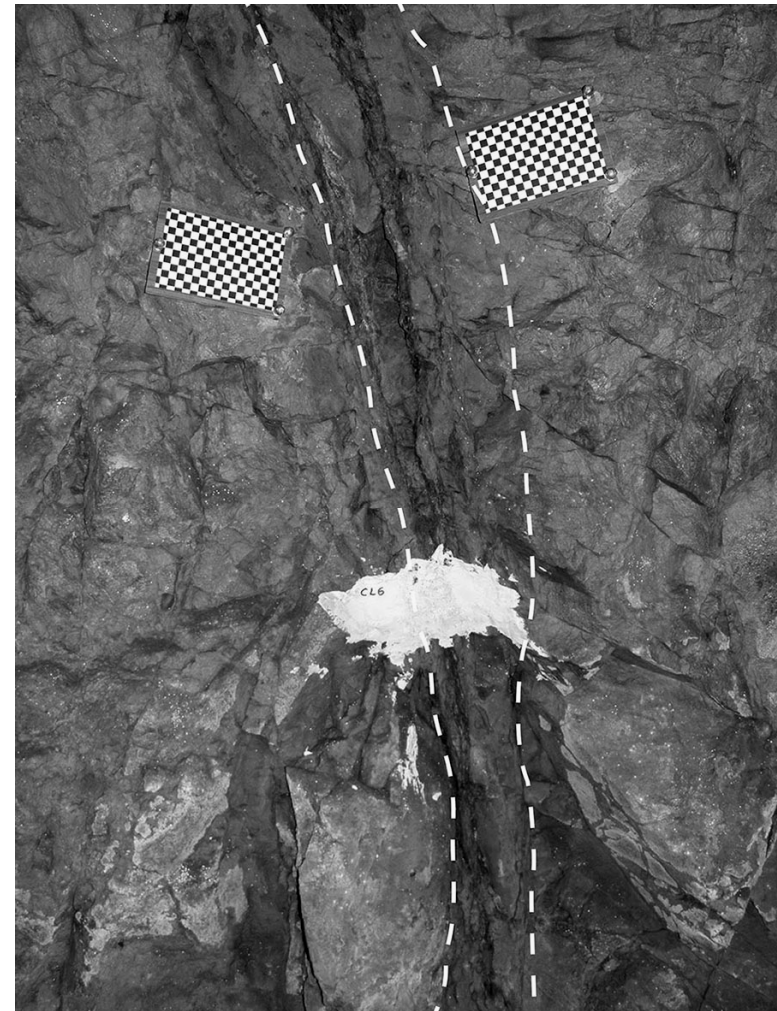

Fig. 2 View of a fragment of side wall with marked outline of the zone of diskontinuity.

generally known (Teisseyre and Sawicki, 1955; Teisseyre and Gawroński, 1965; Teisseyre, 1969; Walczak-Augustyniak, 1988; Kaczorowski and Wojewoda, 2011). Nevertheless these data are insufficient for a comprehensive description of the geological and tectonic situation (Fig. 1). The inspection of GL corridors executed last year revealed the presence of numerous surfaces of discontinuity. Some of them run directly under the measuring instruments which allows for registration of tectonic activity on these faults in real time (tiltings of foundation and vertical motions).

In order to determine the directions of routes and dips angles of all undergrounds lines of dislocation visible in the GL geodetic measurements were executed. In the first phase of works the horizontal measurement network points were stabilized in the corridors. Two points located on the square courtyard of the castle were selected to symlink the points of horizontal measurement network which were measured by Trimble satellite receiver. After adjustment of points of horizontal measurement network were started measurements of each fault. In result a database of coordinates of measuring points were obtained which indicate the routes of 32 measured faults as well as are symlink with the geodetic network. The minimum number of measured points of a single fault which allows to determine route and dip is 3 . Number of measured points for each of faults was in the range 3 to 9 depending on measurement conditions. Coordinates of points on faults as well as points of geodetic horizontal network 


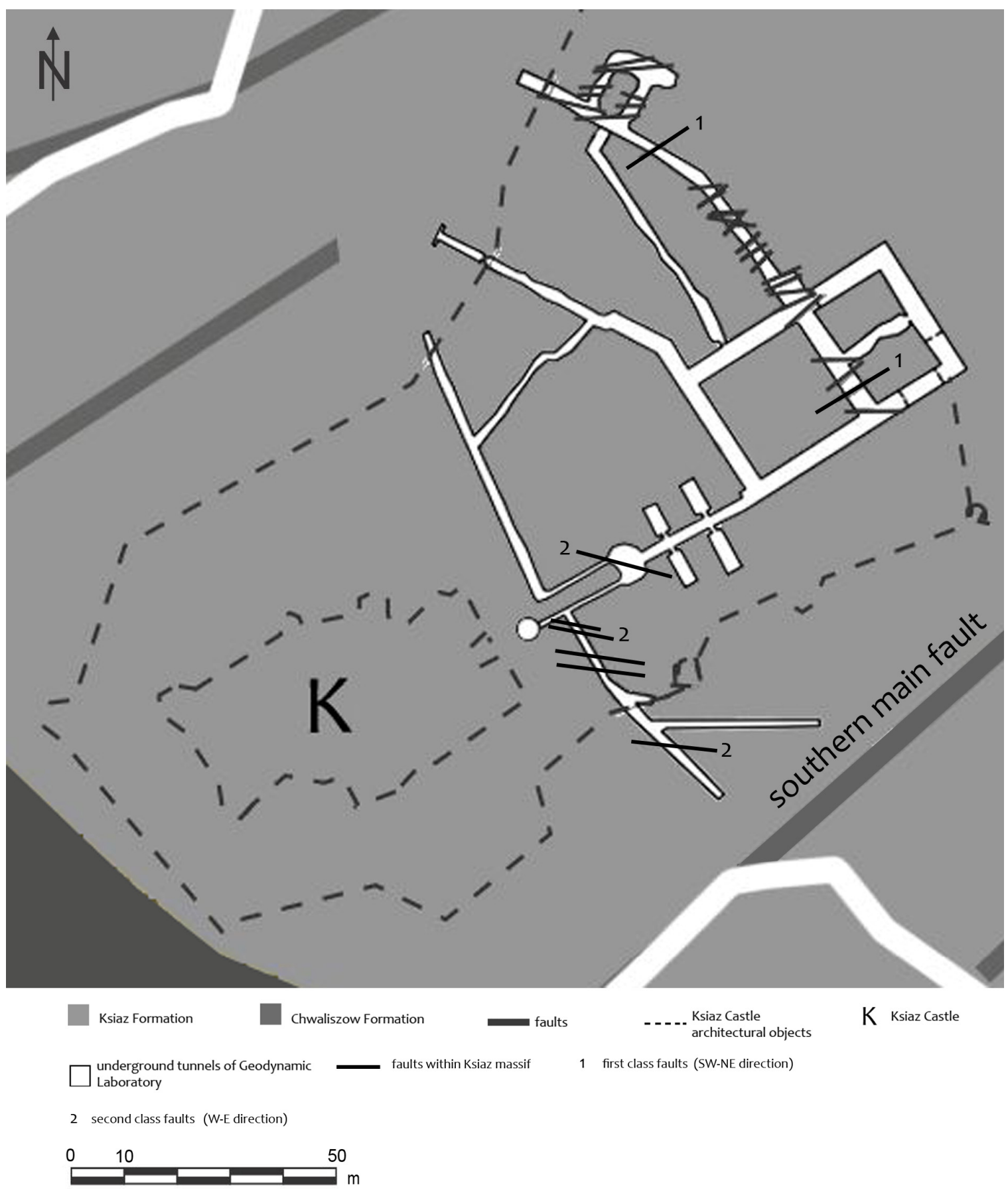

Fig. 3 Mutual position of the elements of the castle, GL underground corridors, southern main fault and faults identified within Ksiaz orogen.

were recorded in the (Polish) National Geodetic Coordinate System "2000” (PL-2000). Coordinates of measurement reference points were determined with millimeter accuracy, while points reflecting outline of fault surface were measured with few centimeters accuracy.

Tectonic structures such as faults are higherlevel surfaces, such as Bézier surface (Muhammad et al., 2009). The method applied for calculating route and dip of each fault bases on the assumption that in the cross-sectional area of corridors (extension of several meters) the fault surface may be approximated with good accuracy by plain interpolation. Thus, the problem of determination of routes and dips of faults demands determination of the equation of plain which fulfills the condition of minimum sum of squares distances between the measured points on the fault and the plain.

Calculation of plain is performed in Cartesian coordinates system $(0, X, Y, Z)$ with the starting point connected to measuring instrument (total station) which position is known in geodetic reference system. In the calculations the equation of a normal plain was used: 


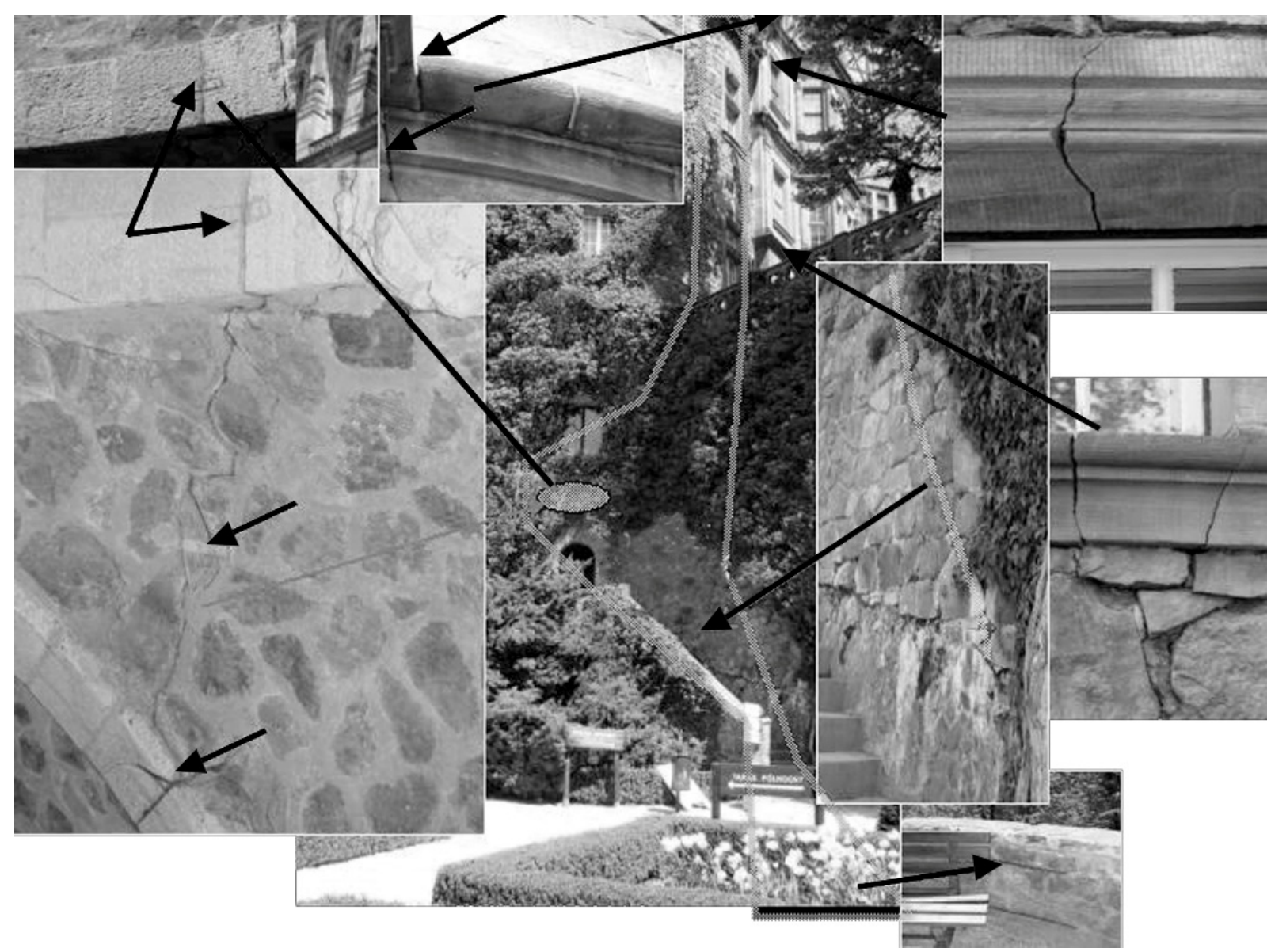

Fig. 4 The linear course of damage zone on Ksiaz Castle architectural objects in south-west section.

$$
0=X \cos (\alpha)+Y \cos (\beta)+Z \cos (\gamma)-p
$$

By mathematical transformation (see Appendix) was obtained a solution of the problem in the form of equation of a line corresponding to the route of the fault, given by:

$Y=-X \frac{W_{1}}{W_{2}}+P \frac{\left(W_{3}-W\right)}{W_{2}}$

while the dip angle of the fault $\gamma$ was determined on the basis of the equation:

$$
\gamma=\arccos \left(\frac{W_{3}}{W}\right)
$$

After determination of routes and dips the estimated surfaces of faults were extrapolated outside the space of GL undergrounds. It allowed to draw lines of intersections of calculated dislocation plains with the numerical model of terrain surface. Intersections of extrapolated plains of faults with terrain surface are treated as geometric place of routes of faults on the surface of the Earth. Analysis of distribution of dislocation surfaces shows that the faults identified in the rock mass can be divided into two classes of faults parallel to each other, located in azimuths W-E and SW-NE (Fig. 3).
Routes of first class faults (SW-NE) comply with the directions of the routes of faults on geological maps (Teisseyre and Gawroński, 1965). Among the faults marked on the geological maps, the most prominent is the southern main fault (Teisseyre and Gawroński, 1965), whose activity has the strongest influence on the morphology of the terrain (Fig. 1 and Fig. 3). This fault is a major element of geological and tectonic model of the Ksiaz orogen. Second class faults with azimuths course towards W-E and faults of the first class of azimuths course towards SW-NE are defined as the secondary.

\section{AREAS OF DAMAGE TO THE ARCHITECTURAL OBJECTS AND ROUTES OF SECONDARY FAULTS}

Documentation of routes of the dislocation surfaces and registrations of indicators of recent tectonic activity determined by GL instruments gave basis for further research on the influence of tectonic deformations on the ground surface and the architectural objects (Blachowski, 2004; Koštak, 2006; Gazetas et al., 2008; Justo et al., 2008; Bray, 2012).

The southern main fault of SW-NE direction has dominating impact on the local morphology of the terrain. It passes the buildings of the castle in the distance of several dozen meters (Fig. 1, Fig. 3 and 


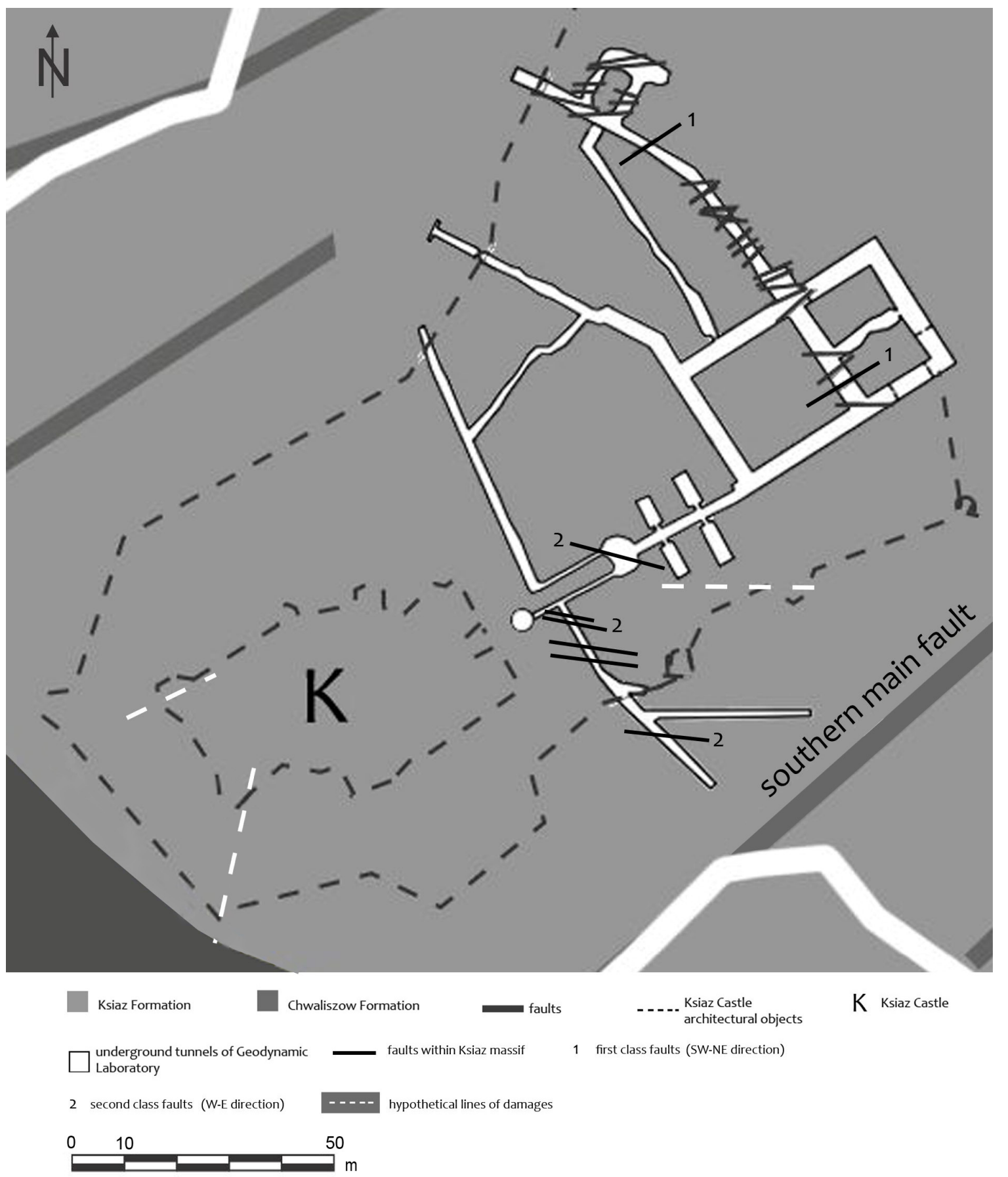

Fig. 5 Map of identified lines of destruction of Ksiaz Castle architectural objects. Mutual position of identified lines of destruction of castle architectural objects and designated lines of the secondary faults.

Fig. 5). Extensions of certain identified in the underground secondary faults of first and second class intersect parts of castle buildings, including the castle walls (Fig. 3). To assess the effects of tectonic interactions, in the first place the secondary faults will be taken into account, whose routes indicate that these faults may intersect the areas of identified damages to architectural objects of Ksiaz. These include faults of both the first and the second class (Fig. 5).

In frame of the works there were noticed some suspected cracks in construction of the wall of St.
George Tower and in the wall of Chestnut Terrace. These damages are repeated in sequences of cracks of window stone elements and in the window sills above the Chestnut Terrace and in the western wall of terraces (fragments repeatedly repaired). Cracks are also visible from the southern side of the castle complex in the stone wall and stairs leading to the terraces - concreted cracks that quickly open again (Fig. 4).

Correlation of azimuths of lines of damages and lines of faults is distinctly visible especially in the 
southern part of the wall (Fig. 5) where the line of identified cracks coincides with the fault azimuth direction - the direction W-E and break lines and damage lines are in close proximity. It may be noted that not all identified zones of damage courses coincide with the directions of documented discontinuity zones.

\section{CONCLUSIONS}

Location of GL nearby the Ksiaz Castle complex in the area of the Sudetes showing recent tectonic activity creates a privileged situation to study the influence of tectonic activity on the architectural complex of the Ksiaz Castle. The area of carried works contains a description of geological and geodetic reconnaissance enabling the identification and location of the dislocation routes in the vicinity of the Ksiaz Castle and underground corridors of laboratory as well as preparation of documentation of the damages to the architectural elements of the castle complex.

Work on the faults determination has revealed the presence of several large and dozens of smaller zones of tectonic fractures (faults) of rock mass isible in the corridor, in which has been installed the watertube tiltmeter. This observation confirms the geodynamic nature of signals recorded by WT generated by vertical movements and the slopes of rock blocks during tectonic events.

Identified faults have been divided into two classes depending on the direction of route. A significant number of faults determined in the underground have running lines similar to the directions of faults plotted on the basis of archival geological maps of Ksiaz Castle surroundings, including the southern main fault.

Extrapolation of faults which are visible inside the orogen (corridors of laboratory) revealed that several faults run directly under the architectural objects of the castle. Designated lines of damages visible in Ksiaz architecture in conjunction with collected information about azimuths of faults allowed to conclude with high probability that observed sequences of damages were produced by effects of recent tectonic activity. Nevertheless, it is necessary to perform empirical verification of the adopted thesis.

For this purpose it is planned further development of measurement infrastructure of GL in Ksiaz through the purchase of new instruments and construction of field geodetic network. Installing on faults the TM-71 crack gauges will allow recording the currently not observed horizontal component of displacements. In further studies of tectonic phenomena will be also used satellite measurement techniques - founded in Ksiaz permanent GNSS stations KSI1 and KSI2 on opposite walls of the southern main fault. The stations KSI1 and KSI2 allow to extend the tectonic phenomena study outside the laboratory, both in direct laboratory surroundings and in relation to regional context.
Development and interpretation of the results of observations will be used for the construction of a research model, applications of which will be used in the description and prediction of the influence of recent - endogenous crustal motions of tectonic origin on land surface and architectural objects.

\section{ACKNOWLEDGMENTS}

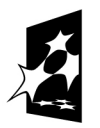

HUMAN CAPITAL

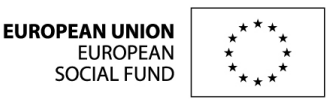

This article is co-financed by the European Union as part of the European Social Fund.

\section{REFERENCES}

Aniszewski, M. and Zagórski, P.: 2006, Underground world of Sowie Range - 2nd edition, extended, TECHNOL, Kraków, (in Polish).

Blachowski, J.: 2004, Tectonic structure as a potential threat to safe operation of the planned Kamieniec Dam. Acta Geodyn. Geomater. 1, No.1(133), 161-170.

Bray, J.D.: 2012, Building near faults. William B. Joyner memorial lecture: Seismological Society of America \& Earthquake Engineering Research Institute.

Chojnicki, T. and Blum, P.A.: 1996, Analysis of ground movements at the Ksiaz observatory in 1974-1993. Artificial Satellites, 31, No. 3, 123-129.

Dudziak, M.: 1996, Secret of Sowie Range - guidebook, JMK, Konin, (in Polish).

Gazetas, G., Pecker, A., Faccioli, E., Paolucci, R. and Anastasopoulos, I.: 2008, Preliminary design recommendations for dip-slip fault-foundation interaction. Bull Earthquake Eng, Springer Science+Business Media B.V. DOI: $10.1007 / \mathrm{s} 10518-008-9082-5$

Grocholski, W.: 1969, Geological guide to the Sudeten Mountains, Wydawnictwa Geologiczne, Warszawa, (in Polish).

Haydukiewicz, A., Olszewski, S., Porębski, S.J. and Teisseyre, A.: 1962, Wałbrzych Sheet - Geological Detailed Map of Sudetes on scale 1:25 000, Państwowy Instytut Geologiczny, Warszawa.

Justo, J.L., Azañón, J.M., Azor, A., Saura, J., Durand, P., Villalobos, M., Morales, A. and Justo, E.: 2008, Neotectonics and slope stabilization at the Alhambra, Granada, Spain. Engineering Geology, 100, No. 3, 101-119. DOI: 10.1016/j.enggeo.2007.12.007

Kaczorowski, M.: 2006, High-resolution wide-range tiltmeter: observations of Earth free oscillations excited by the 26 December 2004 Sumatra-Andaman earthquake. In: Earthquake Source Asymmetry, Structural Media and Rotation Effects, SpringerVerlag, Berlin, 493-520.

Kaczorowski, M.: 2008, Non-tidal plumb line variations observed with help of the long water-tube and horizontal pendulums tiltmeters in Geodynamic Laboratory of PAS in Ksiaz. Reports on Geodesy, 85, 2, 79-86.

Kaczorowski, M.: 2009a, Discussion on strong non-tidal signals registered by horizontal pendulums and water tube tiltmeters in Geodynamic Laboratory of PAS in Ksiaz. Acta Geodyn. Geomater., 6, 3, 369-381. 
Kaczorowski, M.: 2009b, Non-tidal signals of plumb line variations observed with help of the long water-tube tiltmeter, in Geodynamic Laboratory of PAS in Ksiaz. 16th International Symposium on Earth Tides, 1-5 September 2008, Jena. Bulletin d'Information des Marées Terrestres (BIM), 144, 11605-11613.

Kaczorowski, M. and Wojewoda, J.: 2011, Neotectonic activity interpreted from a long water-tube tiltmeter record at the SRC Geodynamic Laboratory in Ksiaz, Central Sudetes, SW Poland. Acta Geodyn. Geomater., 8, No. 3 (163), 249-261.

Koštak, B.: 2006, Deformation effects in rock massifs and their long-term monitoring. Quarterly Journal of Engineering Geology \& Hydrogeology, The Geological Society of London, 39, No. 3, 249-258. DOI: 10.1144/1470-9236/05-024

Marcinowski, R., Piotrowski, J. and Piotrowska, K.: 2004, Dictionary of lithostratigraphic units of Poland, Państwowy Instytut Geologiczny, (in Polish).

Muhammad, M.S., Mahamood, M.T. and Tae-Sun Choi: 2009, Approximating 3D shape using Bezier surface. 2009 IEEE International Conference on Acoustics, Speech and Signal Processing, 753 - 756.

DOI: ieeecomputersociety.org/10.1109/ICASSP.2009.4959693

Nemec, W., Porębski, S.J. and Steel, R.J.: 1980, Texture and structure of resedimented conglomerates: examples from the Książ Formation (Famennian-Tournaisian), south-western Poland. Sedimentology, 27, 519-538. DOI: $10.1111 / \mathrm{j} .1365-3091.1980 / \mathrm{tb} 01645 . x$

Oberc, J.: 1972, Tectonics. Sudeten Mountains and adjacent areas, Wydawnictwo Geologiczne, Warszawa, (in Polish).

Oberc, J.: 1978, The Pre-Assyntian and Assyntian (Baikalian) Elements in South-Western Poland. In: Książkiewicz, M., Oberc, J. and Pożaryski, W. (Eds.): Geology of Poland, Wydawnictwa Geologiczne, Warszawa, 99-173.
Porębski, A.J.: 1981, Świebodzice succession (Upper Devonian-lowest Carboniferous): a prograding mass flow dominated fan-delta complex. Geol. Sudetica, XVI, No. 1, 101-192.

Štepančí́ová, P., Hók, J., Nývlt, D., Dohnal, J., Sýkorová, I. and Stemberk, J.: 2010, Active tectonics research using trenching technique on the south-eastern section of the Sudetic Marginal Fault (NE Bohemian Massif, central Europe). Tectonophysics, 485, 269-282. DOI: $10.1016 /$ j.tecto.2010.01.004

Teisseyre, H.: 1951, The geological structure of Świebodzice Depression. Annales Societatis Geologorum Poloniae, 21, 4, 380-386, (in Polish).

Teisseyre, H.: 1969, Stare Bogaczowice Sheet - Geological Detailed Map of Sudetes on scale 1:25000, Państwowy Instytut Geologiczny, Warszawa.

Teisseyre, H. and Gawroński, O.: 1965, Świebodzice Sheet Geological Detailed Map of Sudetes on scale 1:25 000, Państwowy Instytut Geologiczny, Warszawa.

Teisseyre, H. and Sawicki, L.: 1955, Zagórze Śląskie Sheet - Geological Detailed Map of Sudetes on scale 1:25000, Państwowy Instytut Geologiczny, Warszawa.

Walczak-Augustyniak, M.: 1988, Świdnica Sheet Geological Detailed Map of Sudetes at scale 1:25 000, Państwowy Instytut Geologiczny, Warszawa.

Ziegler, P.A.: 1990, Geological Atlas of Western and Central Europe. 2nd edn., Shell \& Geological Society of London, Bath, 239 pp.

Żelaźniewicz, A. and Aleksandrowski, P.: 2008, Tectonic subdivision of Poland: southwestern Poland. Przegląd Geologiczny, 56, 10, 904-911, (in Polish).

\section{APPENDIX \\ DETERMINATION OF FAULTS PARAMETERS - ROUTE AND ANGLE OF DIP}

Calculation of plain is performed in Cartesian coordinates system $(0, X, Y, Z)$ with the starting point connected to measuring instrument (total station) which position is known in geodetic reference system. In the calculations the equation of a normal plain was used (Fig. 1):

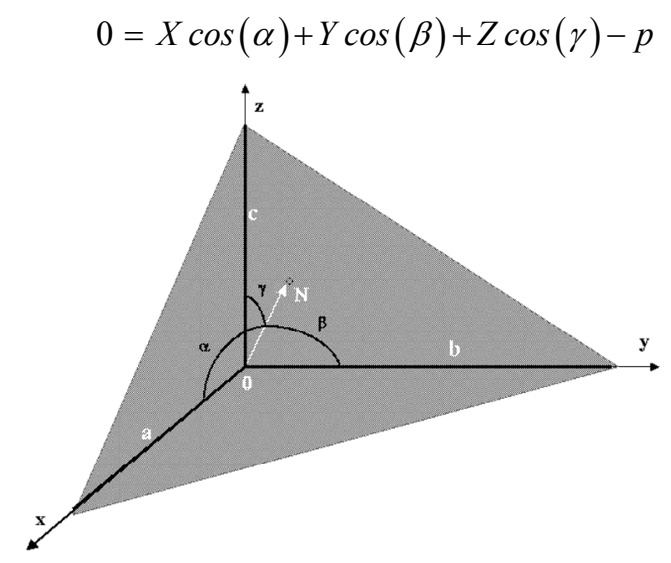

Fig. 1 Graphic illustration of equation of a normal plain. 
In equation (1) $\{\cos (\alpha), \cos (\beta), \cos (\gamma)\}$ are direction cosines of vector $\vec{N}$ normal to the plain the length of which is $p$ (distance between plain and the beginning of Cartesian system) (Fig. 1). Distance of the point $\left(x_{i}, y_{i}, z_{i}\right)$ from the plain is given by the equation:

$$
\delta_{i}\left(x_{i}, y_{i}, z_{i}\right)=x_{i} \cos (\alpha)+y_{i} \cos (\beta)+z_{i} \cos (\gamma)-p
$$

The mathematical task consists in determination of the directional cosines of plain $\{\cos (\alpha), \cos (\beta), \cos (\gamma)\}$ which fulfill the condition of minimum sum $S$ for $N$ measuring points:

$$
S=\sum_{i=1}^{N} \delta_{i}^{2}\left(x_{i}, y_{i}, z_{i}\right)
$$

We substitute: $A=\cos (\alpha), B=\cos (\beta), C=\cos (\gamma)$ into the equation (3) and assume that the distance between the plain and origin of Cartesian system is $\mathrm{p}=1$. The distance of measuring point $\left(x_{i}, y_{i}, z_{i}\right)$ from the plain is equal: $\delta_{i}\left(x_{i}, y_{i}, z_{i}\right)=x_{i} A+y_{i} B+z_{i} C-1$. Therefore function of the sum of squared distances is equal:

$$
S(A, B, C)=\sum_{i=1}^{N} \delta_{i}^{2}\left(x_{i}, y_{i}, z_{i}\right)=\sum_{i=1}^{N}\left(x_{i} A+y_{i} B+z_{i} C-1\right)^{2} .
$$

The criterion $\frac{\partial S}{\partial A}=\frac{\partial S}{\partial B}=\frac{\partial S}{\partial C}=0$ for the minimum of the function $S(A, B, C)$ leads to a system of linear equations:

$$
\begin{aligned}
& \frac{\partial S}{\partial A}=0 \Rightarrow \sum_{i=1}^{N}\left(x_{i} A+y_{i} B+z_{i} C-1\right) x_{i}=A \sum_{i=1}^{N} x_{i}^{2}+B \sum_{i=1}^{N} y_{i} x_{i}+C \sum_{i=1}^{N} z_{i} x_{i}-\sum_{i=1}^{N} x_{i}=0 \\
& \frac{\partial S}{\partial B}=0 \Rightarrow \sum_{i=1}^{N}\left(x_{i} A+y_{i} B+z_{i} C-1\right) y_{i}=A \sum_{i=1}^{N} x_{i} y_{i}+B \sum_{i=1}^{N} y_{i}^{2}+C \sum_{i=1}^{N} z_{i} y_{i}-\sum_{i=1}^{N} y_{i}=0 \\
& \frac{\partial S}{\partial C}=0 \Rightarrow \sum_{i=1}^{N}\left(x_{i} A+y_{i} B+z_{i} C-1\right) z_{i}=A \sum_{i=1}^{N} x_{i} z_{i}+B \sum_{i=1}^{N} y_{i} z_{i}+C \sum_{i=1}^{N} z_{i}{ }^{2}-\sum_{i=1}^{N} z_{i}=0 .
\end{aligned}
$$

Hence:

$$
\left\{\begin{array}{ccc}
\sum_{i=1}^{N} x_{i}^{2} & \sum_{i=1}^{N} y_{i} x_{i} & \sum_{i=1}^{N} z_{i} x_{i} \\
\sum_{i=1}^{N} y_{i} x_{i} & \sum_{i=1}^{N} y_{i}^{2} & \sum_{i=1}^{N} z_{i} y_{i} \\
\sum_{i=1}^{N} z_{i} x_{i} & \sum_{i=1}^{N} z_{i} y_{i} & \sum_{i=1}^{N} z_{i}^{2}
\end{array}\right\}\left[\begin{array}{l}
A \\
B \\
C
\end{array}\right]=\left[\begin{array}{l}
\sum_{i=1}^{N} x_{i} \\
\sum_{i=1}^{N} y_{i} \\
\sum_{i=1}^{N} z_{i}
\end{array}\right]
$$

We calculate the determinants of the matrices $W, W_{1}, W_{2}, W_{3}$ :

$$
W=\left|\begin{array}{ccc}
\sum_{i=1}^{N} x_{i}^{2} & \sum_{i=1}^{N} y_{i} x_{i} & \sum_{i=1}^{N} z_{i} x_{i} \\
\sum_{i=1}^{N} y_{i} x_{i} & \sum_{i=1}^{N} y_{i}^{2} & \sum_{i=1}^{N} z_{i} y_{i} \\
\sum_{i=1}^{N} z_{i} x_{i} & \sum_{i=1}^{N} z_{i} y_{i} & \sum_{i=1}^{N} z_{i}^{2}
\end{array}\right|, W_{1}=\left|\begin{array}{ccc}
\sum_{i=1}^{N} x_{i} & \sum_{i=1}^{N} y_{i} x_{i} & \sum_{i=1}^{N} z_{i} x_{i} \\
\sum_{i=1}^{N} y_{i} & \sum_{i=1}^{N} y_{i}^{2} & \sum_{i=1}^{N} z_{i} y_{i} \\
\sum_{i=1}^{N} z_{i} & \sum_{i=1}^{N} z_{i} y_{i} & \sum_{i=1}^{N} z_{i}^{2}
\end{array}\right|, W_{2}, W_{3}, \text { where }|W| \neq 0 .
$$

By using Cramer's formulas we obtain roots $A=\frac{W_{1}}{W}, B=\frac{W_{2}}{W}, C=\frac{W_{3}}{W}$ of equations (4). Hence, the direction cosines of the searched plain are following: 


$$
\cos (\alpha)=\frac{W_{1}}{W}, \cos (\beta)=\frac{W_{2}}{W}, \cos (\gamma)=\frac{W_{3}}{W} .
$$

Determination of the direction cosines of plain allows to calculate distance $p_{i}$ between origin of Cartesian system and $i$ point on the basis of equation (2) $p_{i}=x_{i} \frac{W_{1}}{W}+y_{i} \frac{W_{2}}{W}+z_{i} \frac{W_{3}}{W}$.

We assume that determined plain which lies in the plain of the fault is in the distance equal to arithmetic mean of distances $\left\{p_{i}\right\}$ of determined point for $N$ on the fault $P=\frac{1}{N} \sum_{i=1}^{N} p_{i}$.

After substitution of $P$ and directional cosines in equation (1) the searched plain corresponding to the plain of the fault is in the form:

$$
P=X \frac{W_{1}}{W}+Y \frac{W_{2}}{W}+Z \frac{W_{3}}{W}
$$

We can find the direction of fault trend by intersecting this plain with the horizontal plain $Z=P$. Hence, straight line equation corresponding to the route of the fault is given by the equation:

$$
Y=-X \frac{W_{1}}{W_{2}}+P \frac{\left(W_{3}-W\right)}{W_{2}}
$$

and the dip angle of the fault is given by the equation:

$$
\gamma=\arccos \left(\frac{W_{3}}{W}\right) \quad \text { Fig. 1) }
$$

